\title{
Renal Artery Stenosis in the Patient with Hypertension: Prevalence, Impact and Management
}

This article was published in the following Dove Press journal: Integrated Blood Pressure Control

\author{
Rohini Manaktala \\ Jose D Tafur-Soto \\ Christopher J White (ID \\ Ochsner Clinic Foundation, Department \\ of Cardiovascular Medicine, New \\ Orleans, LA, USA
}

\begin{abstract}
Atherosclerosis is the primary cause of renal artery stenosis. Atherosclerotic renal artery stenosis (ARAS) is associated with three clinical problems: renovascular hypertension, ischemic nephropathy and cardiac destabilization syndrome which pose huge healthcare implications. There is a significant rate of natural disease progression with worsening severity of renal artery stenosis when renal revascularization is not pursued in a timely manner. Selective subgroups of individuals with ARAS have had good outcomes after percutaneous renal artery stenting (PTRAS). For example, individuals that underwent PTRAS and had improved renal function were reported to have a $45 \%$ survival advantage compared to those without improvement in their renal function. Advances in the imaging tools have allowed for better anatomic and physiologic measurements of ARAS. Measuring translesional hemodynamic gradients has allowed for accurate assessment of ARAS severity. Renal revascularization with PTRAS provides a survival advantage in individuals with significant hemodynamic renal artery stenosis lesions. It is important that we screen, diagnosis, intervene with invasive and medical treatments appropriately in these high-risk patients.
\end{abstract}

Keywords: atherosclerotic renal artery stenosis, ARAS, percutaneous renal artery stenting, PTRAS, renin-angiotensin-aldosterone system, RAAS, acute decompensated heart failure, ADHF, chronic kidney disease, CKD, optimal medical therapy, OMT

\section{Introduction}

Atherosclerosis is by far the most prevalent etiology of renal artery stenosis. Atherosclerotic renal artery stenosis (ARAS) contributes to the development and progression of systemic atherosclerotic disease. It stems from having a hemodynamically significant renal artery atherosclerotic lesion that causes upregulation of the renin-angiotensin-aldosterone system (RAAS) resulting in accelerated hypertension that then adversely impacts pre-existing cardiovascular disease. Additionally, ARAS can also cause three clinical problems: renovascular hypertension, ischemic nephropathy and cardiac destabilization syndrome that include, acute decompensated heart failure (ADHF), recurrent ADHF and acute coronary syndromes (ACS). The prevalence of ARAS identified by Doppler ultrasound (DUS) within a US Medicare population ranges from $0.5 \%$ to $7 \%$ of individuals. ${ }^{1}$ ARAS accounts for $10-20 \%$ of individuals with end stage renal disease who are on dialysis. ${ }^{2}$ Furthermore, concurrent diagnosis of coronary artery disease (CAD) among individuals with ARAS ranges from $11.3 \%$ to $39 \% .^{3}$ There is a significant
Correspondence: Rohini Manaktala Atrium Tower, Room \#3D718, 1514 Jefferson Highway, New Orleans, LA 70121 , USA

Tel + I 504-842-0879

Fax + I 504-842-3278

Email Rohini.manaktala@ochsner.org
Integrated Blood Pressure Control 2020:13 7I-82

$7 \mathbf{1}$

submit your manuscript

(c) (7) (5) 2020 Manaktala et al. This work is published and licensed by Dove Medical Press Limited. The full terms of this license are available at https://www.dovepress.com/ (c)
the work you hereby accept the Terms. Non-commercial uses of the work are permitted without any further permission from Dove Medical Press Limited, provided the work is properly attributed. For permission for commercial use of this work, please see paragraphs 4.2 and 5 of our Terms (https://www.dovepress.com/terms.php). 
rate of natural disease progression with worsening severity of renal artery stenosis shown by previous studies reporting the progression of ARAS by $50 \%$ at 5 years. ${ }^{4}$

Randomized clinical trials have not shown a benefit for renal artery stenting in the management of ARAS when used as an adjunct treatment to optimal medical therapy (OMT) ${ }^{5-7}$ However, selective sub-groups of individuals with ARAS that include those with resistant hypertension, ischemic nephropathy and cardiac destabilization syndrome have had good outcomes after percutaneous renal artery stenting (PTRAS). ${ }^{8}$ Measuring translesional hemodynamic gradients allows for accurate assessment of ARAS severity and identifies patients likely to benefit from stenting. ${ }^{9-11}$ Advances in the imaging tools used to make anatomic and physiologic measurements of ARAS can facilitate identifying the best candidates for PTRAS. These technologies include: blood oxygenation leveldependent magnetic resonance imaging (BOLD MRI), dynamic contrast-enhanced MRI, intravascular ultrasound (IVUS) and renal frame counts. Moreover, research efforts have identified biomarkers such as brain natriuretic peptide (BNP) that may aid in patient selection. ${ }^{12} \mathrm{~A}$ small series of patients with BNP greater than $80 \mathrm{pg} / \mathrm{mL}$ obtained better blood pressure control after undergoing PTRAS. ${ }^{12}$

From experimental animal models, ARAS was found to cause inflammation resulting in microvascular damage via ischemia, fibrosis and apoptosis of cells. ${ }^{13}$ These findings led to the development of low-energy shock wave therapy that improved microcirculation. ${ }^{14}$ ARAS is known to be a progressive disease. However, studies have shown similar long-term clinical outcomes with no difference in mortality or event-free survival in ARAS individuals who initially develop impaired renal function with initiation of medications compared to those individuals without decline in renal function that are also on medical therapy. ${ }^{15}$ Regarding disease progression, the 2-year cumulative incidence is $6 \%$ of ARAS individuals with greater than $60 \%$ stenosis of the renal artery who develop reduction in renal length by greater than $1 \mathrm{~cm} .{ }^{16,17}$ A natural history study of individuals with high-grade ARAS, who were medically managed without renal revascularization, was performed to determine the rate of progression to renal failure and development of accelerated hypertension. This study showed that over 3-year follow-up the number of antihypertensive medications to effectively control blood pressure in this patient population increased. ${ }^{18}$ Additionally, renal function declined and mortality risk rose specifically in those patients with bilateral ARAS or ARAS with a solitary functioning kidney. ${ }^{18}$
Observational studies have shown that PTRAS in individuals with ARAS who also have concomitant chronic kidney disease (CKD) can improve or stabilize renal function and preserve kidney size. ${ }^{19}$ Renal size assessed by pole-to-pole kidney length with ultrasound measurement is an important predictor of clinical response. ${ }^{20}$ Overall, renal revascularization with PTRAS provides patient survival advantage in those with significant hemodynamic renal artery stenosis lesions and advanced CKD (stage 4 and stage 5). ${ }^{21}$ It is important that we screen, diagnosis, intervene with invasive and medical treatments appropriately in these high-risk patients.

\section{Pathophysiology}

Physician scientist, Goldblatt conducted foundational animal experiments investigating the effect of unilateral and bilateral renal artery stenosis on systemic blood pressure. $^{21,22}$ Restricting blood flow to one kidney with a functioning contralateral kidney resulted in upregulation of the neurohormonal pathway of RAAS. The affected juxtaglomerular apparatus of the nephron senses the low flow state and releases renin. Renin then causes systemic vasoconstriction and affects the efferent arteriole of the unaffected kidney causing an increased glomerular filtration rate (GFR) and a pressure diuresis. Over time, the unaffected kidney develops hypertensive nephropathy, no longer able to maintain pressure diuresis, so systemic hypertension ensues. Aldosterone, which is also released from the RAAS, promotes sodium and water retention. In bilateral ARAS or a solitary kidney with significant ARAS, Goldblatt found a state of fluid retention due to decreased diuresis because of the absence of an unaffected kidney to balance the fluid retention, so volume-dependent hypertension develops. ${ }^{23}$

Individuals with clinically significant ARAS also suffer from cardiovascular disease. These individuals experience proinflammatory effects on their cardiovascular system resulting in the development of: smooth muscle cell proliferation, endothelial cell dysfunction, arterial medial hypertrophy, myocardial fibrosis and plaque rupture. ${ }^{24}$

\section{Clinical Conditions}

ARAS is associated with three main clinical disease processes that include: renovascular hypertension, cardiac destabilization syndromes and ischemic nephropathy. Renovascular hypertension is defined as an increase in arterial pressure caused by hemodynamically significant renal artery stenosis. ${ }^{25}$ In this disease, resistant (refractory) 
Table I Functional Classification of ARAS in Association with Hypertension $^{26}$

\begin{tabular}{|l|l|}
\hline Grade & Description \\
\hline I & $\begin{array}{l}\text { Asymptomatic ARAS with normotensive blood pressure } \\
\text { and normal renal function } \\
\text { II }\end{array}$ \\
ARAS with well controlled hypertension using medical \\
III & $\begin{array}{l}\text { ARAS with uncontrolled hypertension despite optimal } \\
\text { medical therapy or clinical signs of volume overload and } \\
\text { abnormal renal function }\end{array}$ \\
\hline
\end{tabular}

Note: Data from Rocha-Singh et al. ${ }^{26}$

hypertension develops which is difficult to control blood pressure despite maximally tolerated doses of three antihypertensive agents including a diuretic. In these individuals, after they undergo PTRAS they experience a significant reduction and/or normalization in their blood pressure. ${ }^{26} \mathrm{~A}$ functional classification system has been developed to categorize ARAS and associated hypertension (Table 1). ${ }^{26}$ Cardiac destabilization syndromes include: "flash" pulmonary edema events, ADHF and ACS. ${ }^{27-30}$ Pickering syndrome describes a specific condition seen in individuals that have bilateral ARAS as they lack the compensatory mechanism of a functional kidney in regulating the body's salt and fluid balance. These individuals also have hypertension and are prone to frequent "flash" pulmonary edema episodes. Ischemic nephropathy is a condition where local ischemia to the kidney causes tubulointerstitial injury and microvascular damage. $^{31}$ This creates a state of oxidative injury that leads to the production of cytokines and inflammation resulting in interstitial fibrosis and renal atrophy. ${ }^{31}$

\section{Diagnostic Modalities}

The American College of Cardiology (ACC) and American Heart Association (AHA) clinical practice guidelines describe a variety of diagnostic imaging tools such as: DUS, computed tomography angiography (CTA) and magnetic resonance angiography (MRA) as screening tests to aid in the diagnosis of ARAS. ${ }^{28}$ When noninvasive imaging tests are inconclusive and there is high degree of clinical suspicion for ARAS then catheter angiography is indicated. ${ }^{32-35}$ To eliminate the inter-observer variability in the visual estimation of renal artery stenosis, a translesional pressure gradient is measured (ratio of the distal pressure to proximal pressure across the stenosis) to determine if ARAS is hemodynamically significance.
A lesion is hemodynamically significant if on renal angiography the stenosis is $50-70 \%$ with a peak translesional gradient of at least $20 \mathrm{mmHg}$ or a mean gradient of at least $10 \mathrm{mmHg} .{ }^{34}$ However, angiographic ARAS lesions do not always indicate that there is renal ischemia. Newer technologies such as: BOLD MRI and dynamic contrastenhanced MRI are used to quantify the degree of renal ischemia by measuring decreased renal tissue oxygenation with experimental-graded reduction in renal blood flow. ${ }^{35}$ Although these imaging modalities are still being researched they have the potential to aid in distinguishing between viable and non-viable kidneys. Table 2 compares the various imaging modalities for the detection of ARAS. $^{32-38}$ There are additional diagnostic tests that assess both the functional and physiological changes when evaluating ARAS and the interaction between the stenotic lesion and activation of RAAS. Table 3 compares three physiologic diagnostic tests for ARAS. ${ }^{39-41}$

\section{Optimal Medical Therapy}

Lifestyle modifications with diet, physical activity and smoking cessation in addition to optimal medical therapy (OMT) are the initial steps for newly diagnosed ARAS. Furthermore, co-morbidities such as hypertension, hyperlipidemia and diabetes need to be well managed as they contribute to the deterioration in renal function and accelerate the disease progression in ARAS. The ACC and AHA recommend the use of an angiotensin-converting enzyme inhibitor (ACE-I) or angiotensin II receptor blocker (ARB) and calcium channel blockers for medical therapy in treatment of hypertension in the setting of ARAS. ${ }^{42,43}$ There is also evidence to support the use of other antihypertensive agents such as: thiazides, hydralazine, alpha-blockers and beta-blockers in addition to diuretics to effectively control blood pressure. ACE-I and ARB are $86 \%$ to $92 \%$ effective in lowering blood pressure in individuals with ARAS and should be one of the agents in their antihypertensive medication regimen. ${ }^{43}$ However, individuals with ARAS and solitary functioning kidney, severe bilateral renal artery stenosis or advanced chronic kidney disease should be cautiously monitored while on ACE-I or ARB therapy as there is a slight risk for acute renal failure. ${ }^{43}$ There have been no randomized-controlled studies studying the effects of various medical regimens on the management of hypertension associated with ARAS. This is due to individuals with ARAS having refractory hypertension and requiring multiple antihypertensive medications. Statin and antiplatelet therapies are 
Table 2 Imaging Modalities Utilized for Diagnosing ARAS ${ }^{32-38}$

\begin{tabular}{|c|c|c|}
\hline Imaging Test & Advantages & Disadvantages \\
\hline $\begin{array}{l}\text { Doppler } \\
\text { Ultrasound } \\
(\text { DUS })^{32}\end{array}$ & $\begin{array}{l}\text {-able to pinpoint the exact location of ARAS } \\
\text {-the degree of stenosis can be identified with direct } \\
\text { visualization of renal arteries and doppler velocity } \\
\text { measurements of blood flow } \\
\text {-PSV }>200 \mathrm{~cm} / \mathrm{s} \text { has a } 95 \% \text { sensitivity and } 90 \% \text { specificity for } \\
\text { renal artery stenosis }>50 \% \\
\text {-utilized to follow up after PTRAS and monitor for restenosis }\end{array}$ & $\begin{array}{l}\text { - insufficient evaluation of accessory renal arteries in } \\
\text { overweight individuals } \\
\text { - presence of bowel gases impairs visualization of the renal } \\
\text { artery } \\
\text { - the quality of study is dependent on the operator }\end{array}$ \\
\hline $\begin{array}{l}\text { Computerized } \\
\text { Tomographic } \\
\text { Angiography } \\
(\text { CTA })^{33}\end{array}$ & $\begin{array}{l}\text { - there is high spatial resolution and increased speed of image } \\
\text { acquisition } \\
\text {-the sensitivity is } 94 \% \text { and specificity is } 93 \% \text { for a renal artery } \\
\text { stenosis lesion greater than } 50 \%\end{array}$ & $\begin{array}{l}\text { - lack of information on renal flow or pressure distal to RAS } \\
\text {-radiation exposure } \\
\text { - risks associated with using iodinated contrast } \\
\text { - there is increased risk of nephrotoxic effects of the } \\
\text { contrast }\end{array}$ \\
\hline $\begin{array}{l}\text { Magnetic } \\
\text { Resonance } \\
\text { Angiography } \\
(\text { MRA })^{33}\end{array}$ & $\begin{array}{l}\text { - allow for visualization of the renal artery without the need } \\
\text { for ionizing radiation } \\
\text {-can obtain hemodynamic data such as, increased blood flow } \\
\text { turbulence } \\
\text {-can be used to evaluate in-stent restenosis } \\
\text {-the sensitivity is } 96 \% \text { and specificity is } 92 \% \text { in detecting renal } \\
\text { artery stenosis greater than or equal to } 50 \%\end{array}$ & $\begin{array}{l}\text { - there is a risk of causing nephrogenic systemic fibrosis } \\
\text { with gadolinium contrast in patients with severe renal } \\
\text { insufficiency or dialysis dependency }\end{array}$ \\
\hline $\begin{array}{l}\text { Arterial } \\
\text { Angiography }{ }^{34}\end{array}$ & $\begin{array}{l}\text { - usually follows a positive non-invasive screening test first } \\
\text { and is the gold standard for diagnosing ARAS } \\
\text {-there is better accuracy in identifying hemodynamically } \\
\text { significant stenosis via measurement of the translesional } \\
\text { pressure gradient }\end{array}$ & $\begin{array}{l}\text { - risks associated with the procedure include: vascular } \\
\text { access related complications, embolization, radiation } \\
\text { exposure, iodinated contrast related reaction and contrast } \\
\text { induced nephropathy }\end{array}$ \\
\hline BOLD MRI ${ }^{36}$ & $\begin{array}{l}\text { - an accurate way of monitoring renal tissue oxygenation and } \\
\text { degree of renal hypoxia in ARAS by measuring levels of } \\
\text { serum injury biomarkers in the draining renal vein } \\
\text {-correlate with the severity of renal blood flow obstruction } \\
\text { - can monitor therapeutic interventions or pretreatment } \\
\text { with adjunct cellular based therapies for ARAS before renal } \\
\text { revascularization is pursued }\end{array}$ & - its use is restricted to research setting presently \\
\hline $\begin{array}{l}\text { Dynamic Contrast } \\
\text { Enhanced } M \mathrm{MI}^{35}\end{array}$ & $\begin{array}{l}\text { - can measure single kidney glomerular filtration rate, tissue } \\
\text { perfusion and vascularity which can better characterize the } \\
\text { overall functionality of the kidney and determine directly } \\
\text { irreversible renal parenchymal damage } \\
\text {-it can be used to assess functional outcomes after renal } \\
\text { artery revascularization }\end{array}$ & $\begin{array}{l}\text { - affected by respiratory motion artifacts } \\
\text { - the contrast agent has the potential of causing } \\
\text { nephrotoxicity especially in patients with severe chronic } \\
\text { kidney disease } \\
\text { - there is a lack of standard imaging and analysis protocols }\end{array}$ \\
\hline $\begin{array}{l}\text { Intravascular } \\
\text { Ultrasound } \\
\text { (IVUS) }^{37}\end{array}$ & $\begin{array}{l}\text { - characterize renal artery plaque } \\
\text { - well validated imaging modality to guide optimal stent } \\
\text { implantation }\end{array}$ & $\begin{array}{l}\text { - it is of low quality and low resolution imaging compared to } \\
\text { optical coherence tomography (OCT) intravascular imaging } \\
\text {-it is difficult to decipher fine details such as stent strut } \\
\text { versus thrombus }\end{array}$ \\
\hline $\begin{array}{l}\text { Renal Frame } \\
\text { Count }^{38}\end{array}$ & $\begin{array}{l}\text { - an intraprocedural tool that can assess and quantify } \\
\text { perfusion of kidneys in determining the severity of ARAS and } \\
\text { predict a clinical response after PTRAS }\end{array}$ & $\begin{array}{l}\text { - there is risk of azotemia from the nephrotoxic effects of } \\
\text { the contrast }\end{array}$ \\
\hline
\end{tabular}


Table 3 Physiologic Diagnostic Tests Used to Diagnose ARAS ${ }^{39-41}$

\begin{tabular}{|c|c|c|}
\hline Test & Advantages & Disadvantages \\
\hline $\begin{array}{l}\text { Plasma Renin } \\
\text { Activity }\end{array}$ & $\begin{array}{l}\text {-it can be used in procedural setting to predict which individuals with } \\
\text { ARAS will have improvement in their resistant hypertension after } \\
\text { PTRAS }\end{array}$ & $\begin{array}{l}\text { - affected by physiological parameters (blood volume, } \\
\text { sodium load, unilateral versus bilateral renal disease, } \\
\text { age, race, sex and comorbidities) which can alter the } \\
\text { circulating levels of renin } \\
\text {-the test's sensitivity is } 57 \% \text { and specificity is } 66 \%\end{array}$ \\
\hline $\begin{array}{l}\text { Captopril } \\
\text { Renography }\end{array}$ & $\begin{array}{l}\text { - provides functional data with regards to GFR reduction with ARAS } \\
\text { with angiotensin converting enzyme inhibitor (ACE-I) compared to the } \\
\text { increase GFR in contralateral side } \\
\text {-measures the plasma aldosterone concentration (PAC), plasma renin } \\
\text { concentration (ARC) and plasma renin activity (PRA) } \\
\text {-Diagnosis of renovascular hypertension made by PAC/ARC >40 or } \\
\text { PAC/PRA > } 200 \\
\text {-sensitivity of the test is } 74 \% \text { while the specificity is } 59 \%\end{array}$ & $\begin{array}{l}\text {-it cannot specify anatomical location of renal artery } \\
\text { lesion } \\
\text {-not a reliable test in those with poor renal function } \\
\text { and bilateral renal disease }\end{array}$ \\
\hline $\begin{array}{l}\text { Bilateral Renal } \\
\text { Vein Renin } \\
\text { Assay }\end{array}$ & $\begin{array}{l}\text {-the renal vein renin ratio is the renin level of the ischemic kidney } \\
\text { compared to the contralateral kidney which allows selection of } \\
\text { individuals with hypertension and ARAS who may benefit from } \\
\text { interventions } \\
\text {-in } 90 \% \text { of the situations these individuals will respond to treatment }\end{array}$ & $\begin{array}{l}\text {-high false positives and negatives, both are } 67 \% \\
\text {-difficult to differentiate hypertensive individuals with } \\
\text { unilateral and bilateral ARAS and many of them will } \\
\text { have essential hypertension rather than renin-mediated } \\
\text { therefore necessitating the use of additional studies } \\
\text { (doppler ultrasound and catheter based renal } \\
\text { arteriography) }\end{array}$ \\
\hline
\end{tabular}

also indicated in medical treatment of ARAS given that ARAS is a peripheral vascular disease. ${ }^{44,45}$

\section{Clinical Trials}

Three randomized-controlled trials have been conducted to compare PTRAS with OMT to OMT alone. The Cardiovascular Outcomes in Renal Atherosclerotic Lesions (CORAL), Angioplasty and Stenting for Renal Artery Lesions (ASTRAL) and Stent Placement in Patients with Atherosclerotic Renal Artery Stenosis and Impaired Renal Function (STAR) trials did not show PTRAS to be superior to OMT in the ARAS population with mild to moderate stenosis. $^{5-7}$ The lack of benefit for PTRAS was attributed to 1) a selection of patients with mild to moderate ARAS and low-risk features and 2) the lack of hemodynamic confirmation of the severity of mild to moderate ARAS. These studies did not enroll high-risk participants who had resistant (refractory) hypertension, cardiac destabilization syndromes or ischemic nephropathy.

The CORAL trial compared OMT alone to PTRAS with OMT in individuals with ARAS. These low-risk patients had hypertension with a systolic blood pressure of $155 \mathrm{~mm} \mathrm{Hg}$ or higher while receiving two or more antihypertensive medications or had CKD with GFR of less than $60 \mathrm{~mL} / \mathrm{min} / \mathrm{m}^{2}$ calculated from the Modification of Diet in Renal Disease (MDRD) formula and attributed their hypertension or CKD to ARAS. The mean ARAS stenosis for randomized patients was $67.3 \%$, and hemodynamic translesional gradients were not measured in moderate ARAS $(50-70 \%$ lesions $) .^{7}$ Primary endpoints included: mortality, renal function, and occurrence of adverse cardiovascular and renal events. They did not find any statistical difference after 43 months follow-up between the two groups. ${ }^{7}$ Specifically, stent treatment did not influence GFR over 3 years in participants receiving RAAS inhibitor medical therapy along with strict control of traditional risk factors for renal disease and atherosclerosis such as hypertension, hyperlipidemia and diabetes. However, there was a difference of $2.3 \mathrm{mmHg}$ reduction in systolic blood pressure favoring PTRAS. ${ }^{7}$

The ASTRAL trial enrolled patients with an uncertain indication for PTRAS. These patients either had refractory hypertension or unexplained impaired renal function that was suggestive of ARAS. They underwent imaging either in the form of DUS, CTA, MRA or renal angiography. Physicians were unsure if these patients would benefit from renal revascularization. So they were randomized in the trial into an OMT group and OMT plus PTRAS group. They found that there were no benefits from PTRAS in terms of improving renal function or reducing 
cardiovascular events and deaths. ${ }^{5}$ There was a small reduction in mean systolic blood pressure by $1.6 \mathrm{mmHg}$ in the revascularization group compared to the control group. ${ }^{5}$ The experience and skill of the interventionalists performing PTRAS were questioned due to $9 \%$ complication rate reported in this trial. ${ }^{5}$

The STAR trial also compared renal artery stenting and OMT versus OMT alone for individuals with mild to moderate ARAS. Study participants had ARAS with greater than $50 \%$ stenotic lesion, estimated creatinine clearance $(\mathrm{eCrCl})$ by Cockcroft-Gault equation with less than $80 \mathrm{~mL} / \mathrm{min} / 1.73 \mathrm{~m}^{2}$ and stable blood pressure less than $140 / 90 \mathrm{mmHg}^{8}$. The primary endpoint investigated was progression of renal disease defined as greater than $20 \%$ decrease in $\mathrm{eCrCl}$ from baseline within first two years of follow-up. There was no observed benefit with PTRAS over only medical treatment on the progression of CKD. However, it is important to take into consideration that $30 \%$ of the patients randomized to the renal revascularization group had ARAS with a lesion less than $50 \%{ }^{6}$

Observational cohort studies, in patients with high-risk ARAS have shown beneficial effects such as better hypertension management with renal stenting compared to OMT alone in treatment of patients with ARAS. The Herculink Elite Renal Stent to Treat Renal Artery Stenosis (HERCULES) trial studied individuals with ARAS that had greater than or equal to $60 \%$ stenosis detected by angiogram along with uncontrolled hypertension (on average taking 3.4 antihypertensive medications) and randomized them to OMT therapy alone or with PTRAS. The study's endpoints included: change in blood pressure, antihypertensive medication regimen and renal function comparing baseline with 9 months follow-up. Renal revascularization via PTRAS was shown to have a statistically significant reduction in systolic blood pressure and stable kidney function. ${ }^{46}$

Furthermore, studies were performed investigating the treatment options for ARAS and their effect on the progression of left ventricular hypertrophy in patients with CAD and ARAS. The renal artery stenosis in coronary artery disease trial showed neither PTRAS with medical therapy or medical therapy alone led to significant change in renal function at 1-year follow-up. ${ }^{47}$ However, both groups had a statistically significant reduction in left ventricular mass index. ${ }^{47}$ Moreover, the Cardiac Benefits of Renal Artery Stenting (CARMEL) study showed marked improvement in left ventricular filling pressures in individuals with ARAS and heart failure after undergoing PTRAS. ${ }^{48}$
There are two randomized trials that have yet to publish their results. The Nephropathy Ischemic Therapy (NITER) trial randomized ARAS individuals into two arms: OMT alone versus OMT and PTRAS. The patients selected had stable chronic kidney disease (GFR $>30 \mathrm{~mL} / \mathrm{min} / \mathrm{m}^{2}$ ), hypertension and hemodynamically significant renal luminal lesion greater than $70 \%$ diagnosed by DUS and confirmed by MRA. ${ }^{49}$ The clinical endpoints include: initiation of dialysis, reduction of GFR by greater than $20 \%$ and death. The other trial is the Medical and Endovascular Treatment of Atherosclerotic Renal Artery Stenosis (METRAS), which had a similar intervention arm and enrolled similar participants from the ARAS population. Their main clinical endpoint is the GFR value in the ischemic kidney determined by renal scintigraphy. Additional endpoints include: reduction in blood pressure reading, improvement in quality of life and prevention of cardiovascular events. ${ }^{50}$

Overall, published randomized control trials did not show differences in cumulative endpoint outcomes such as: blood pressure reduction, cardiovascular and cerebrovascular events, and change in renal function (decline, stabilization, improvement) or death compared to the observational trials. This is likely due to several factors. First of all, there was selection bias starting with the low-risk patients enrolled in the randomized trials. For example, participants in the ASTRAL trial had stable underlying chronic kidney disease, baseline $\mathrm{eCrCl}$ of $40 \mathrm{~mL} / \mathrm{min} / 1.73 \mathrm{~m}^{2}$ and it is not surprising to see that were no significant changes in renal function in either groups. Moreover, these patients did not have resistant hypertension and the inclusion criteria for blood pressure management varied considerably with blood pressure readings and number of medications used. Also, individuals with severe ARAS may not always have clinical manifestations. This was seen in the patient population of the ASTRAL trial who were asymptomatic and majority had ARAS incidentally diagnosed. That is why there is no justification for PTRAS of incidentally discovered ARAS. Additional factors that limited the application of these randomized control trials findings include: small sample size and short time interval with follow-up. Since these were intention to treat designed trials, the increased cross-over rate from the conservative therapy arm also influenced the overall results. See Table 4 for summary of the top three clinical trials regarding PTRAS among the ARAS patient population.

\section{Renal Revascularization}

Renal revascularization using PTRAS in select groups of individuals with severe ARAS has proven to be beneficial. 
Table 4 Comparison of Randomized Control Trials for OMT versus OMT and PTRAS in ARAS

\begin{tabular}{|c|c|c|c|}
\hline $\begin{array}{l}\text { Name of } \\
\text { Clinical } \\
\text { Trial }\end{array}$ & ASTRAL $^{5}$ (806 Participants) & STAR $^{6}$ (140 Participants) & CORAL $^{7}$ (947 Participants) \\
\hline $\begin{array}{l}\text { Severity of } \\
\text { ARAS }\end{array}$ & $\begin{array}{l}\text { Any degree of ARAS (confirmed by DUS, } \\
\text { CTA, MRA and renal angiography) }\end{array}$ & $\begin{array}{l}\text { At least } 50 \% \text { ARAS (seen on CTA, MRA } \\
\text { and renal angiography) }\end{array}$ & $\begin{array}{l}\text { At least } 80 \% \text { ARAS (seen on DUS, CTA } \\
\text { or MRA) }\end{array}$ \\
\hline $\begin{array}{l}\text { Inclusion } \\
\text { Criteria of } \\
\text { Blood } \\
\text { Pressure }\end{array}$ & Uncontrolled or resistant hypertension & Stable BP $<140 / 90 \mathrm{mmHg}$ on medication & $\begin{array}{l}\text { Systolic BP greater than } 155 \mathrm{mmHg} \text {, on } \\
\text { two anti-hypertensive medications }\end{array}$ \\
\hline $\begin{array}{l}\text { Inclusion } \\
\text { Criteria of } \\
\text { Renal } \\
\text { Disease }\end{array}$ & $\begin{array}{l}\text { Any degree of unexplained renal } \\
\text { dysfunction }\end{array}$ & $\mathrm{CrCl}<80 \mathrm{~mL} / \mathrm{min} / 1.73 \mathrm{~m}^{2}$ & eGFR of less than $60 \mathrm{~mL} / \mathrm{min} / 1.73 \mathrm{~m}^{2}$ \\
\hline $\begin{array}{l}\text { Exclusion } \\
\text { Criteria }\end{array}$ & $\begin{array}{l}\text {-Surgical renal revascularization required } \\
\text { or high likelihood will be needed within } 6 \\
\text { months } \\
\text {-Previous revascularization for renal } \\
\text { artery stenosis } \\
\text {-Nonatheromatous cardiovascular disease }\end{array}$ & $\begin{array}{l}\text {-Proven cholesterol embolization at } \\
\text { previous interventions } \\
\text {-Any known cause of renal failure other } \\
\text { than ischemic nephropathy } \\
\text {-Pulmonary edema in the presence of } \\
\text { bilateral renovascular disease in } \\
\text { combination with intolerance of ACE-I or } \\
\text { angiotensin-II antagonist defined as } \\
\text { a decline in eCrCl }>20 \% \\
\text {-Myocardial infarction or cerebrovascular } \\
\text { accident less than } 3 \text { months } \\
\text {-Renal artery diameter }<4 \mathrm{~mm}\end{array}$ & $\begin{array}{l}\text {-Renal artery stenosis due to } \\
\text { fibromuscular dysplasia } \\
\text {-CKD from another cause besides } \\
\text { ischemic nephropathy } \\
\text {-CKD associated with a serum creatinine } \\
\text { level greater than } 4 \mathrm{mg} / \mathrm{dL} \text { or kidney } \\
\text { length less than } 7 \mathrm{~cm} \\
\text {-Renal artery stenosis lesion that could } \\
\text { not be treated with the use of a single } \\
\text { stent }\end{array}$ \\
\hline Follow-Up & 34 months & 24 months & 43 months \\
\hline Endpoints & $\begin{array}{l}\text { Primary: change in renal function } \\
\text { Secondary: blood pressure control, time } \\
\text { to first renal event, time to first } \\
\text { cardiovascular event and mortality }\end{array}$ & $\begin{array}{l}\text { Primary: reduction in creatinine clearance } \\
\text { greater than } 20 \% \text { compared to baseline } \\
\text { Secondary: safety, cardiovascular } \\
\text { morbidity and mortality }\end{array}$ & $\begin{array}{l}\text { Primary: composite of cardiovascular or } \\
\text { renal death, myocardial infarction, stroke, } \\
\text { hospitalization for ADHF, progressive } \\
\text { renal insufficiency and need for dialysis }\end{array}$ \\
\hline Results & $\begin{array}{l}\text {-The rate of progression of renal impairment } \\
\text { was lower in the revascularization group.- } \\
\text { Blood pressure readings decreased but } \\
\text { without significant difference between the } \\
\text { two groups. }\end{array}$ & $\begin{array}{l}\text { Approximately } 16 \% \text { in the PTRAS group } \\
\text { and } 22 \% \text { in the OMT alone group had } \\
\text { a } 20 \% \text { or greater decrease in creatinine } \\
\text { clearance. }\end{array}$ & $\begin{array}{l}\text {-No significant difference in rate of } \\
\text { primary end points or all cause mortality } \\
\text { was seen.-There was a difference in } \\
\text { systolic blood pressure seen in the PTRAS } \\
\text { group. }\end{array}$ \\
\hline Limitations & $\begin{array}{l}\text {-Approximately } 25 \% \text { of study participants } \\
\text { in each group had normal renal function at } \\
\text { the entry of the trial. -Some participants } \\
\text { identified as having } 50-70 \% \text { stenosis in } \\
\text { actuality had stenosis of }<50 \% \text {. -There } \\
\text { was a high complication rate ( } 9 \% \text { in the } \\
\text { first } 24 \text { hours) after PTRAS. -It was a non- } \\
\text { blinded trial so observer and selection } \\
\text { bias was present. -Nearly } 6 \% \text { of the study } \\
\text { participants crossed over from OMT to } \\
\text { intervention group. -There was low } \\
\text { power to detect difference in subgroups. }\end{array}$ & $\begin{array}{l}\text {-Study participants were falsely identified } \\
\text { with ARAS by non-invasive imaging and } \\
\text { some did not require stenting. } \\
\text {-Complication rates were high. }\end{array}$ & $\begin{array}{l}\text {-Study participants were not medically } \\
\text { optimized on their blood pressure } \\
\text { medications. } \\
\text {-Participants with severe ARAS were } \\
\text { withdrawn from study. } \\
\text {-ARAS was not confirmed to have } \\
\text { hemodynamic significance. } \\
\text {-Participants with mild stenosis were also } \\
\text { included and randomized to PTRAS. }\end{array}$ \\
\hline
\end{tabular}


Table 5 Procedural Complications Seen with PTRAS ${ }^{56}$

\begin{tabular}{|l|l|}
\hline Procedural Complication & $\begin{array}{l}\text { Percentage of } \\
\text { Patients Affected }\end{array}$ \\
\hline 30 day mortality & $1 \%$ \\
Worsening of renal function & $4 \%$ \\
Acute renal failure & $2 \%$ \\
Segmental kidney infarction & $1-2 \%$ \\
Need for surgical intervention for either & $2 \%$ \\
nephrectomy or salvage & \\
Groin hematoma and puncture site trauma & $3-5 \%$ \\
Occlusion of the renal artery & $2-3 \%$ \\
Symptomatic embolization & $3 \%$ \\
Death & $1 \%$ \\
\hline
\end{tabular}

Note: Data from Ruzsa et al. ${ }^{56}$

Severe ARAS is defined as a luminal stenosis of $>70 \%$, or if the stenosis is between $50 \%$ and $70 \%$ a trans-stenotic peak pressure gradient greater than $20 \mathrm{mmHg}$ or mean pressure gradient greater than $10 \mathrm{mmHg}$ is required. ${ }^{26,27}$ Clinical guidelines support stenting ARAS in individuals with an established indication for renal revascularization. Revascularization in patients with severe ARAS is indicated in the following individuals: (i) cardiac destabilization syndromes: flash pulmonary edema with severe hypertension, (ii) resistant (refractory) hypertension and (iii) rapidly progressive ischemic nephropathy, chronic kidney disease with GFR less than $45 \mathrm{cc} / \mathrm{min} / \mathrm{m}^{2}$ and global renal ischemia. ${ }^{26,51}$ Observational studies have shown that after renal revascularization, ARAS individuals have improvement in their New York Heart Association (NYHA) functional class and fewer hospitalizations for ADHF. $^{29,52}$ These individuals also have better controlled blood pressure. Renal revascularization in addition to coronary intervention for individuals with cardiac destabilization syndromes results in significant improvement in their left ventricular filling pressure. ${ }^{29,30}$

PTRAS with drug-eluting stents (DES) were studied in The Palmaz Genesis Peripheral Stainless Steel Balloon Expandable Stent in Renal Artery Treatment (GREAT) trial that compared sirolimus DES to bare-metal stents (BMS). ${ }^{53}$ They observed no procedural complications, stent implantation failure/displacement or need for additional stent implantation in patients with ARAS who underwent PTRAS. The binary restenosis rate was $6.7 \%$ for DES versus $14.6 \%$ for the BMS $(p=0.30) .{ }^{53}$ With regard to the long-term procedural success of PTRAS, it is important to look at the long-term patency rates. Stent restenosis is $10-20 \%$ after 5 years of follow-up. ${ }^{54,55}$ Factors that promote long-term stent patency include short stent length and good implantation technique.

The reported rate of procedural complications with PTRAS in the first 30 days is low in experienced operator hands (Table 5). ${ }^{56}$ The CORAL trial reported renal artery dissection in $2.2 \%$, branch-vessel occlusion in $1.2 \%$ and distal embolization in $1.2 \%{ }^{6}$ Other complications associated with PTRAS include: stent misplacement, access-vessel damage, stent embolization, renal artery thrombosis or occlusion and

Table 6 American College of Cardiology Appropriate Use Criteria for Treatment of ARAS

\begin{tabular}{|c|c|c|}
\hline Clinical Scenario* & $\begin{array}{l}\text { Percutaneous Renal } \\
\text { Artery Stenting }\end{array}$ & $\begin{array}{l}\text { Class and Level } \\
\text { of Evidence }\end{array}$ \\
\hline $\begin{array}{l}\text { Sudden presentation of flash pulmonary edema } \\
\text { Bilateral ARAS or a solitary viable kidney with ARAS along with declining renal function } \\
\text { Failure to control blood pressure on three maximally treated medications (one of which is } \\
\text { a diuretic) } \\
\text { Recurrent ADHF requiring hospitalization despite being on maximal medical treatment } \\
\text { Unilateral ARAS with declining renal function } \\
\text { ACS while being on OMT } \\
\text { Well controlled blood pressure on two or more antihypertensive medications } \\
\text { Uncontrolled blood pressure on less than three antihypertensive medications } \\
\text { Incidentally discovered unilateral ARAS (severe ARAS 70-99\% stenosis or } 50-69 \% \text { stenosis } \\
\text { with hemodynamic significance) } \\
\text { Incidentally discovered bilateral ARAS or solitary kidney (severe ARAS } 70-99 \% \text { stenosis or } \\
50-69 \% \text { stenosis with hemodynamic significance) } \\
\text { Unilateral ARAS, bilateral ARAS or a solitary kidney with borderline (50-69\% stenosis } \\
\text { without hemodynamic confirmation of severity) }\end{array}$ & $\begin{array}{l}\text { Appropriate } \\
\text { Appropriate } \\
\text { May be appropriate } \\
\text { May be appropriate } \\
\text { May be appropriate } \\
\text { May be appropriate } \\
\text { Rarely appropriate } \\
\text { Rarely appropriate } \\
\text { Rarely appropriate } \\
\text { Rarely appropriate } \\
\text { Rarely appropriate }\end{array}$ & $\begin{array}{l}\text { Class I, LOE B } \\
\text { Class Ila, LOE B } \\
\text { Class Ila, LOE B } \\
\text { Class I, LOE B } \\
\text { Class Ilb, LOE C } \\
\text { Class Ila, LOE B }\end{array}$ \\
\hline
\end{tabular}

Notes: $*$ Significant ARAS $=$ moderate $(50 \%-70 \%)$ ARAS with a resting/hyperemic translesional mean gradient of $\geq 10 \mathrm{~mm} \mathrm{Hg}$, systolic gradient $\geq 20 \mathrm{~mm} \mathrm{Hg} /$ or severe $(>70 \%)$ ARAS. Data from Bailey et al. ${ }^{51}$ 
death. ${ }^{6}$ Alternative access sites (such as: radial and brachial artery) to femoral artery access are preferred due to most individuals with ARAS having concurrent peripheral artery disease and the associated risk with femoral vascular complications. ${ }^{57}$ A "no-touch" technique has been adopted for PTRAS where a second 0.035 -inch $\mathrm{J}$ wire is placed within the guide catheter that is sitting within the renal artery to minimize contact between the guide catheter and atherosclerotic plaque. $^{58}$ This ultimately prevents cholesterol embolization. $^{58}$

Percutaneous renal artery interventions are also associated with the risk of distal embolization. Preventative measures include the use of embolic protection device (EPDs). The Renal Artery Stenting With or Without Distal Protection Device and Use of a Platelet Aggregator Inhibitor (RESIST) were a prospective-randomized study that evaluated the safety and efficacy of PTRAS along with glycoprotein IIb/ IIIa inhibitor (abciximab) and EPD on renal function. Platelets secrete soluble CD40 ligand (sCD40L) which promotes platelet activation. GP IIb/IIIa inhibits platelet activation. In this study, participants were randomized to one of the four groups: (1) EPD only, (2) no EPD and no abciximab, (3) abciximab only and (4) EPD and abciximab. Of those study participants who received EPD with renal revascularization, $26 \%$ of them had captured emboli in their filter. ${ }^{59}$ Participants that were randomized to the EPD and abciximab showed significant decrease in sCD40L after PTRAS. Findings revealed that individuals that received abciximab and EPD during their renal artery stenting had stable or improved renal function compared to the controls. ${ }^{59}$

Intravascular ultrasound (IVUS) is commonly utilized with PTRAS to aid in stent sizing and confirming apposition of the stent to the arterial wall. IVUS can reveal detailed information on the plaque morphology and accurately measure vessel diameter so operators of PTRAS can predict in advance which lesions are at risk for complications after interventions. ${ }^{60}$ In a large case series study conducted at a single center site, the role of IVUS with PTRAS was evaluated. ARAS cases where IVUS was performed in conjunction with PTRAS and achieved good angiographic result required only additional therapeutic interventions in $23.5 \%$ of the cases. ${ }^{60}$ This could be explained by $14.4 \%$ of the stents having incomplete stent apposition/expansion, $5.2 \%$ of renal arteries having dissections and $3.9 \%$ of the stents not covering the ostia. ${ }^{60}$ Additional stenting was needed in $4.5 \%$ of the arteries that were treated. It is found that restenosis most often occurs in renal arteries with a diameter of less than $4.5 \mathrm{~mm}^{10}$. IVUS allows for successful placement of these stents while minimizing the risk of vessel wall rupture. ${ }^{8}$ Overall, IVUS is used to achieve optimal stenting results by safely delivering the appropriate size stent with hopes of reducing future occurrence of developing renal artery restenosis. ${ }^{60}$

\section{Follow-Up}

Patients should be followed clinically in terms of blood pressure control with laboratory results to monitor renal function, and surveillance DUS imaging is recommended to evaluate stent patency. DUS is the recommended imaging technique to screen for in-stent restenosis (ISR). DUS surveillance monitoring for renal stent patency should take into account that a stented artery is less compliant than a native artery and that peak systolic velocity (PSV) and systolic renal to aortic ratio (RAR) obtained by DUS are higher for any given degree of arterial narrowing within the stent; therefore, obtaining a post-procedure DUS is reasonable to establish a new baseline PSV. ${ }^{61}$ ISR based on DUS is defined as greater than $70 \%$ stenosis and peak systolic velocity (PSV) greater than $395 \mathrm{~cm} / \mathrm{s} .{ }^{61}$ Patients should have routine 30-day, 3-month, 6-month, 12-month and annual clinical, laboratory, and DUS follow-up for surveillance of ISR. ${ }^{61}$

\section{Guidelines and Appropriate Use Criteria (AUC)}

The ACC/AHA guidelines for treating ARAS stem from the peripheral artery disease guidelines created in $2006 .{ }^{27,28}$ These recommendations are based on expert opinion, and observational studies. In 2018 Society for Cardiovascular Angiography and Interventions (SCAI) produced an appropriate use criteria (AUC) statement for renal artery stenting. They reported stenting as an appropriate treatment in specific groups of individuals with ARAS with severe stenosis. ${ }^{28} \mathrm{See}$ Table 6 for summary of AUC for treatment of ARAS. ${ }^{27,28}$

\section{Conclusion}

The clinical outcome of individuals with ARAS depends on both the degree of underlying renal parenchymal damage and atherosclerotic burden. In randomized control trials, the recruited patients had low-risk ARAS with $<70 \%$ stenosis and underlying normal to mildly reduced renal function. ${ }^{62}$ The selection of low-risk participants impacted the results of the trials. The subanalysis of the trials showed that participants with ARAS of $80 \%$ or greater along with acute presentation of ADHF, unstable angina, rapid deterioration of renal function and severe uncontrolled hypertension significantly benefited from renal revascularization in addition to $\mathrm{OMT}^{62}$ 
It may be worthwhile determining which ARAS patients have hibernating renal parenchyma along with functionally significant stenosis that can truly benefit from renal revascularization. Long-term outcomes of individuals with ARAS can be improved potentially from interventions such as, stem cell therapies that can inhibit oxidative injury and inflammation to the renal parenchyma and cardiovascular system. ${ }^{63}$ These adjunct therapies could change the natural disease progression and improve their morbidity and mortality rate in individuals with ARAS. However, further investigative studies will need to prove that these therapies provide a renoprotective benefit.

\section{Disclosure}

There are no relationships with industry. The authors report no conflicts of interest in this work.

\section{References}

1. Kalra P, Guo H, Kausz A, et al. Atherosclerotic renovascular disease in United States patients aged 67 years or older: risk factors, revascularization and prognosis. Kidney Int. 2005;68(1):293-301. doi:10.1111/j.1523-1755.2005.00406.x

2. Scoble J. The epidemiology and clinical manifestations of atherosclerotic renal disease. In: Renal Vascular Disease. London, UK: WB Saunders Co, Ltd; 1996:303-314.

3. Payami B, Jafarizade M, Mousavi S, Sattari S, Nokhostin F. Prevalence and predictors of atherosclerotic renal artery stenosis in the hypertensive patients undergoing simultaneous coronary and renal angiography: a cross-sectional study. J Renal Inj Prev. 2016;5 (1):34-38. doi:10.15171/jrip.2016.08

4. Schreiber M, Pohl M, Novick A. The natural history of atherosclerotic and fibrous renal artery disease. Urol Clin North Am. 1984;11(3):383-392.

5. Wheatley K, Ives N, Gray R, et al. Revascularization versus Medical Therapy for Renal-Artery Stenosis. N Engl J Med. 2009;361:1953-1962.

6. Bax L, Mali W, Buskens E, et al. The benefit of stent placement and blood pressure and lipid-lowering for the prevention of progression of renal dysfunction caused by atherosclerotic ostial stenosis of the renal artery. the star-study: rationale and study design. $J$ Nephrol. 2003;16(6):807-812.

7. Cooper C, Murphy T, Cutlip D, et al. Stenting and medical therapy for atherosclerotic renal-artery stenosis. $N$ Engl J Med. 2014;370 (1):13-22. doi:10.1056/NEJMoa1310753

8. Lederman R, Mendelsohn F, Santos R, Phillips H, Stack R, Crowley J. Primary renal artery stenting: characteristics and outcomes after 363 procedures. $\mathrm{Am}$ Heart J. 2001;142(2):314-323. doi:10.1067/mhj.2001.116958

9. Mitchell J, Subramanian R, White C, et al. Predicting Blood pressure improvement in hypertensive patients after renal artery stent placement: renal fractional flow reserve. Catheter Cardiovasc Interv. 2007;69(5):685-689. doi:10.1002/ccd.21095

10. Leesar M, Varma J, Shapira A, et al. Prediction of hypertension improvement after stenting of renal artery stenosis: comparative accuracy of translesional pressure gradients, intravascular ultrasound, and angiography. J Am Coll Cardiol. 2009;53(25):2363-2371. doi:10.1016/j.jacc.2009.03.031

11. Mangiacapra F, Trana C, Sarno G, et al. Translesional pressure gradients to predict blood pressure response after renal artery stenting in patients with renovascular hypertension. Circ Cardiovasc Interv. 2010;3 (6):537-542. doi:10.1161/CIRCINTERVENTIONS.110.957704
12. Silva J, Chan A, White C, et al. Elevated brain natriuretic peptide predicts blood pressure response after stent revascularization in patients with renal artery stenosis. Circulation. 2005;111 (3):328-333. doi:10.1161/01.CIR.0000153271.77341.9F

13. Sun D, Eirin A, Ebrahimi B, Textor S, Lerman A, Lerman L. Early atherosclerosis aggravates renal microvascular loss and fibrosis in swine renal artery stenosis. $J$ Am Soc Hypertens. 2016;10 (4):325-335. doi:10.1016/j.jash.2016.01.019

14. Zhang X, Krier J, Carrascal C, et al. Low- energy shockwave therapy improves ischemic kidney microcirculation. JASN. 2016;27 (12):3715-3724. doi:10.1681/ASN.2015060704

15. Cooper E, Xie Y, Nguyen H, et al. Early rapid decline in kidney function in medically managed patients with atherosclerotic renal artery stenosis. $J$ Am Heart Assoc. 2019;8(11). doi:10.1161/JAHA.119.012366

16. Zierler R, Bergelin R, Isaacson J, Strandness D. Natural history of atherosclerotic renal artery stenosis: a prospective study with duplex ultrasonography. J Vasc Surg. 1994;19(2):250-257. doi:10.1016/S07415214(94)70100-8

17. Caps M, Zierler R, Polissar N, et al. Risk of atrophy in kidneys with atherosclerotic renal artery stenosis. Kidney Int. 1998;53(3):735-742. doi:10.1046/j.1523-1755.1998.00805.x

18. Chabova V, Schirger A, Stanson A, McKusick M, Textor S. Outcomes of atherosclerotic renal artery stenosis managed without revascularization. Mayo Clin Proc. 2000;75(5):437-444. doi:10.1016/S0025-6196(11)64210-9

19. Watson P, Hadjipetrou P, Cox S, Piemonte T, Eisenhauer A. Effect of renal artery stenting on renal function and size in patients with atherosclerotic renovascular disease. Circulation. 2000;102 (14):1671-1677. doi:10.1161/01.CIR.102.14.1671

20. Kalra P, Chrysochou C, Green D, et al. The benefit of renal artery stenting in patients with atheromatous renovascular disease and advanced chronic kidney disease. Catheter Cardiovasc Interv. 2010;75(1):1-10. doi:10.1002/ccd.22290

21. Goldblatt H, Lynch J, Hanzal R, Summerville W. Studies on experimental hypertension: $i$. the production of persistent elevation of systolic blood pressure by means of renal ischemia. J Exp Med. 1934;59(3):347-379. doi:10.1084/jem.59.3.347

22. Cohen J, Townsend R. Use of renin-angiotensin system blockade in patients with renal artery stenosis. CJASN. 2014;9(7):1149-1152. doi: $10.2215 / \mathrm{CJN} .04240414$

23. Hocher B, George I, Rebstock J, et al. Endothelin system- dependent cardiac remodeling in renovascular hypertension. Hypertension. 1999;33(3):816-822. doi:10.1161/01.HYP.33.3.816

24. Herrmann S, Textor S. Current concepts in the treatment of renovascular hypertension. Am J Hypertens. 2018;31(2):139-149. doi:10.1093/ajh/hpx154

25. Van der Niepen P, Rossignol P, Lengele J, et al. Renal artery stenosis in patients with resistant hypertension: stent it or not? Curr Hypertens Rep. 2017;19(5). doi:10.1007/s11906-017-0703-8

26. Rocha-Singh K, Eisenhauer A, Textor S, et al. Atherosclerotic peripheral vascular disease symposium ii: interventional for renal artery disease. Circulation. 2008;118(25):2873-2878. doi:10.1161/ CIRCULATIONAHA.108.191178

27. Klein A, Jaff M, Gray B, et al. SCAI appropriate use criteria for peripheral arterial interventions: an update. Catheter Cardiovasc Interv. 2017;90(4):E90-E110. doi:10.1002/ccd.27141

28. Hirsch A, Haskal Z, Hertzer N, et al. ACC/AHA 2005 practice guidelines for the management of patients with peripheral arterial disease (lower extremity, renal, mesenteric, and abdominal aortic): a collaborative report from the american association for vascular surgery/society for vascular surgery, society for cardiovascular angiography and interventions, society for vascular medicine and biology, society of interventional radiology, and the acc/aha task force on practice guidelines. Circulation. 2006;113(11): e463-e654. doi:10.1161/CIRCULATIONAHA.106.174526 
29. Messerli F, Bangalore S, Makani H, et al. Flash pulmonary edema and bilateral renal artery stenosis: the Pickering syndrome. Eur Heart J. 2011;32(18):2231-2235. doi:10.1093/eurheartj/ehr056

30. Khosla S, White C, Collins T, Jenkins J, Shaw D, Ramee S. Effects of renal artery stent implantation in patients with renovascular hypertension presenting with unstable angina or congestive heart failure. Am J Cardiol. 1997;80(3):363-366. doi:10.1016/S00029149(97)00368-8

31. Garcia-Donaire J, Alcazar J. Ischemic nephropathy: detection and therapeutic intervention. Kidney Int. 2005;68(99):S131-S136. doi:10.1111/j.1523-1755.2005.09924.x

32. Schaberle W, Leyerer L, Schierling W, et al. Ultrasound diagnostics of renal artery stenosis. Gefasschirurgie. 2016;21(S1):4-13. doi:10.1007/s00772-015-0060-3

33. Rountas C, Vlychou M, Liakopoulos V, et al. Imaging modalities for renal artery stenosis in suspected renovascular hypertension: prospective intraindividual comparison of color doppler US, CT angiography, GD-enhanced MR angiography, and digital substraction angiography. Ren Fail. 2007;29(3):295-302. doi:10.1080/ 08860220601166305

34. McLaughlin K, Jardine A, Moss J. Renal artery stenosis. BMJ. 2000;320(7242):1124-1127. doi:10.1136/bmj.320.7242.1124

35. Lim S, Chrysochou C, Buckley D, Kalra P, Sourbron S. Prediction and assessment of responses to renal artery revascularization with dynamic contrast-enhanced magnetic resonance imaging: a pilot study. Am J Physiol Renal Physiol. 2013;305(5):F672-F678. doi:10.1152/ajprenal.00007.2013

36. Ebrahimi B, Textor S, Lerman L. Renal Relevant radiology: renal functional magnetic resonance imaging. Clin J Am Soc Nephrol. 2014;9(2):395-405. doi:10.2215/CJN.02900313

37. Waksman R, Kitabata H, Prati F, Albertucci M, Mintz G. Intravascular ultrasound versus optical coherence tomography guidance. J Am Coll Cardiol. 2013;67(17):S32-S40. doi:10.1016/j.jacc.2013.08.709

38. Naghi J, Palakodeti S, Ang L, Reeves R, Patel M, Mahmud E. Renal Frame Count: A Measure Of Renal Flow That Predicts Success Of Renal Artery Stenting In Hypertensive Patients. Catheter Cardiovasc Interv. 2015;86(2):304-309. doi:10.1002/ccd.25946

39. Kotiliar C, Inserra F, Forcada P. Are plasma renin activity and aldosterone levels useful as a screening test to differentiate between unilateral and bilateral renal artery stenosis in hypertensive patients? J Hypertens. 2010;28(3):594-601. doi:10.1097/HJH.0b013e32833487d4

40. Stratigis S, Stylianou K, Kyriazis P, et al. Renal artery stenting for atherosclerotic renal artery stenosis identified in patients with coronary artery disease: does captopril renal scintigraphy predict outcomes? J Clin Hypertens. 2018;20(2):373-381. doi:10.1111/jch.13160

41. Taylor A, Fletcher J, Nally J, et al. Procedure guideline for diagnosis of renovascular hypertension. society of nuclear medicine. $\mathrm{J} \mathrm{Nucl}$ Med. 1998;39(7):1297-1302.

42. Badila E, Tintea E. How to manage renovascular hypertension. An article from the e-journal of the ESC council for cardiology practice. ESC. 2014;13:8-9.

43. Muneer K, Nair A. Angiotensin-converting enzyme inhibitors and receptor blockers in heart failure and chronic kidney diseaseDemystifying controversies. Indian Heart J. 2017;69(3):371-374. doi:10.1016/j.ihj.2016.08.007

44. Silva V, Martin L, Franco R, et al. Pleiotropic effects of statins may improve outcomes in atherosclerotic renovascular disease. $\mathrm{Am}$ J Hypertens. 2008;21(10):1163-1168. doi:10.1038/ajh.2008.249

45. Berger J, Krantz M, Kittelson J, Hiatt W. Aspirin for the prevention of cardiovascular events in patients with peripheral artery disease. a meta-analysis of randomized trials. JAMA. 2009;301(18):1909-1919. doi:10.1001/jama.2009.623

46. Jaff M, Bates M, Sullivan T, et al. Significant reduction in systolic blood pressure following renal artery stenting in patients with uncontrolled hypertension: results from the HERCULES trial. Catheter Cardiovasc Interv. 2012;80(3):343-350. doi:10.1002/ccd.24449
47. Marcantoni C, Zanoli L, Rastelli S, et al. Stenting of renal artery stenosis in coronary artery disease (ras-cad) study: a prospective, randomized trial. J Nephrol. 2009;22(1):13-16.

48. Kawarada O, Kume T, Nakamura S, et al. Cardiac function response to stenting in atherosclerotic renal artery disease with and without heart failure: results from the Carmel study. ESC Heart Fail. 2019;6 (2):319-327. doi:10.1002/ehf2.12391

49. Scarpioni R, Michieletti E, Cristinelli L, et al. Atherosclerotic renovascular disease: medical therapy versus medical therapy plus renal artery stenting in preventing renal failure progression: the rationale and study design of a prospective, multicenter and randomized trial (NITER). J Nephrol. 2005;18(4):423-428.

50. Rossi G, Seccia T, Miotto D, et al. The medical and endovascular treatment of atherosclerotic renal artery stenosis (METRAS) study: rationale and study design. J Hum Hypertens. 2012;26(8):507-516. doi:10.1038/jhh.2011.62

51. Bailey S, Beckman J, Dao T, et al. ACC/AHA/SCAI/SIR/SVM 2018 appropriate use criteria for peripheral artery intervention: a report of the american college of cardiology appropriate use criteria task force, american heart association, society for cardiovascular angiography and interventions, society of interventional radiology, and society for vascular medicine. J Am Coll Cardiol. 2019;73(2):214-237. doi:10.1016/j.jacc.2018.10.002

52. Gray B, Olin J, Childs M, Sullivan T, Bacharach M. Clinical benefit of renal artery angioplasty with stenting for the control of recurrent and refractory congestive heart failure. Vasc Med. 2002;7 (4):275-279. doi:10.1191/1358863x02vm456oa

53. Sapoval M, Zahringer M, Pattynama P, et al. Low-profile stent system for treatment of atherosclerotic renal artery stenosis: the GREAT trial. $J$ Vasc Interv Radiol. 2005;16(9):1195-1202. doi:10.1097/01. RVI.0000171765.67665.D3

54. Blum U, Krumme B, Flugel P, et al. Treatment of ostial renal-artery stenoses with vascular endoprostheses after unsuccessful balloon angioplasty. $N$ Engl J Med. 1997;336(7):459-465. doi:10.1056/ NEJM199702133360702

55. Henry M, Amor M, Henry I, et al. Stents in the treatment of renal artery stenosis: long-term follow-up. J Endovasc Surg. 1999;6 (1):42-51. doi:10.1583/1074-6218(1999)006<0042:SITTOR>2.0. $\mathrm{CO} ; 2$

56. Ruzsa Z, Toth K, Jambrik Z, et al. Transradial access for renal artery intervention. Interv Med Appl Sci. 2014;6(3):97-103. doi:10.1556/ IMAS.6.2014.3.1

57. Feldman R, Wargovich T, Bittl J. No-touch technique for reducing aortic wall trauma during renal artery stenting. Catheter Cardiovasc Interv. 1999;46(2):245-248. doi:10.1002/(SICI)1522-726X(199902) 46:2<245::AID-CCD27>3.0.CO;2-V

58. Haller S, Adlakha S, Reed G, et al. Platelet activation in patients with atherosclerotic renal artery stenosis undergoing stent revascularization. Clinical Journal of the American Society of Nephrology. 2011;6(9):2185-2191. doi:10.2215/CJN.03140411

59. Campbell J, Stone P, Bates M. Technical discussion of diagnostic angiography and intervention of atherosclerotic renal artery stenosis. Semin Vasc Surg. 2013;26(4):150-160. doi:10.1053/j.semvascsurg.2014.06.002

60. Mohler E, Gornik H, Gerhard-Herman M, et al. ACCF/ACR/AIUM/ ASE/ASN/ICAVL/SCAI/SCCT/SIR/SVM/SVS 2012 appropriate use criteria for peripheral vascular ultrasound and physiological testing part i: arterial ultrasound and physiological testing: a report of the american college of cardiology foundation appropriate use criteria task force, american college of radiology, american institute of ultrasound in medicine, american society of echocardiography, american society of nephrology, intersocietal commission for the accreditation of vascular laboratories, society for cardiovascular angiography and interventions, society of cardiovascular computed tomography, society for interventional radiology, society for vascular medicine, and society for vascular surgery. $J$ Am Coll Cardiol. 2012;60 (3):242-276. doi:10.1016/j.jacc.2012.02.009 
61. Chi Y, White C, Thornton S, Milani R. Ultrasound velocity criteria for renal in-stent restenosis. J Vasc Surg. 2009;50(1):119-123. doi:10.1016/j.jvs.2008.12.066

62. Ritchie J, Kalra P. ASTRAL and beyond: who is appropriate to consider for renal artery revascularization? Vasc Dis Manage. 2011;8:E12-E20.
63. Eirin A, Textor S, Lerman L. Novel therapeutic strategies for renovascular disease. Curr Opin Nephrol Hypertens. 2019;28(4):383-389. doi:10.1097/MNH.0000000000000513

\section{Publish your work in this journal}

Integrated Blood Pressure Control is an international, peer-reviewed open-access journal focusing on the integrated approach to managing hypertension and risk reduction. Treating the patient and comorbidities together with diet and lifestyle modification and optimizing healthcare resources through a multidisciplinary team approach constitute key features of the journal. This journal is indexed on

Submit your manuscript here: https://www.dovepress.com/integrated-blood-pressure-control-journa
American Chemical Society's Chemical Abstracts Service (CAS) The manuscript management system is completely online and includes a very quick and fair peer-review system, which is all easy to use. Visit http://www.dovepress.com/testimonials.php to read real quotes from published authors. 